\title{
Albumin Uptake in OK Cells Exposed to Rotenone: A Model for Studying the Effects of Mitochondrial Dysfunction on Endocytosis in the Proximal Tubule?
}

\author{
A.M. Halla, ${ }^{a}$ M. Campanellab, d A. Loesch ${ }^{c}$ M.R. Duchen ${ }^{b}$ R.J. Unwin ${ }^{a}$ \\ ${ }^{a}$ Centre for Nephrology, ${ }^{b}$ Department of Cell and Developmental Biology, and ${ }^{\mathrm{c} C e n t r e ~ f o r ~ I n f l a m m a t i o n, ~} \mathrm{UCL}$, and \\ ${ }^{\mathrm{d}}$ Royal Veterinary College, University of London, London, UK
}

\section{Key Words}

Proximal tubule $\cdot$ Endocytosis $\cdot$ OK cell $\cdot$ Mitochondrial

dysfunction $\cdot$ Rotenone

\begin{abstract}
Background: The renal proximal tubule (PT) is clinically vulnerable to mitochondrial dysfunction; sub-lethal injury can lead to the Fanconi syndrome, with elevated urinary excretion of low-molecular-weight proteins. As the mechanism that couples mitochondrial dysfunction to impaired PT lowmolecular weight protein uptake is unknown, we investigated the effect of respiratory chain (RC) inhibitors on endocytosis of FITC-albumin in PT-derived OK cells. Methods: Uptake of FITC-albumin was quantified using confocal microscopy. Cytosolic ATP levels were measured in real time using both luciferin/luciferase assays and measurements of free $\left[\mathrm{Mg}^{2+}\right]$. Reactive oxygen species production was measured using mitosox. Results: RC blockade produced only a small decrease in cytosolic ATP levels and had minimal effect on FITC-albumin uptake. Inhibition of glycolysis caused a much bigger decrease in both cytosolic ATP levels and FITCalbumin endocytosis. Rotenone led to higher rates of reactive oxygen species production than other RC inhibitors. Rotenone also caused widespread structural damage on electron microscopy, which was mimicked by colchicine and
\end{abstract}

prevented by taxol; consistent with inhibition of microtubule polymerisation as the underlying mechanism. Conclusions: Endocytosis of FITC-albumin is ATP-dependent in OK cells, but the cells are very glycolytic and therefore represent a poor metabolic model of the PT. Rotenone has toxic extramitochondrial structural effects.

Copyright $\odot 2010$ S. Karger AG, Basel

\section{Introduction}

The renal proximal tubule (PT) is responsible for the uptake of filtered low-molecular-weight proteins (LMWPs) and peptides [1] such as retinol-binding protein, parathyroid hormone and insulin, which have to be reclaimed to prevent their loss in urine. These LMWPs are thought to be scavenged from the luminal fluid by a low-affinity, high-capacity, uptake system, consisting of 2 large receptors situated in the apical membrane, megalin and cubilin [2]. On ligand binding, the receptor-ligand complexes are internalised, via receptormediated endocytosis, in endosomes, which are then acidified to promote dissociation of the ligand from the receptors [3], and the receptors recycled to the luminal membrane.

\section{KARGER}

๑ 2010 S. Karger AG, Basel

Fax +4161306 1234

E-Mail karger@karger.ch

www.karger.com
Accessible online at:

www.karger.com/nep
Dr. A.M. Hall

Centre for Nephrology, UCL, Royal Free Campus

London NW3 2PF (UK)

Tel. +44 207679 7127, Fax +442078130530

E-Mail andrew.hall@ucl.ac.uk 
The large amount of solute transport that occurs in the PT requires energy in the form of ATP that is generated largely by mitochondrial oxidative phosphorylation, which produces more ATP per substrate molecule than anaerobic glycolysis [4]. Clinically the PT is vulnerable to mitochondrial dysfunction from insults such as genetic mitochondrial cytopathy [5], toxic xenobiotics (e.g. antiretroviral therapy $[6,7])$ and ischaemia-reperfusion injury [8]. The reasons for this are unclear, but it has been demonstrated previously in isolated tubules that the PT has very little capacity for anaerobic metabolism [9], and we have shown recently - using multi-photon imaging of rat kidney slices - that mitochondrial function and the response to respiratory chain (RC) inhibition varies along the nephron [10]. Sub-lethal injury in the PT can cause a breakdown in normal transport processes leading to urinary losses of solutes, including LMWPs (the renal Fanconi syndrome [11]). The pathogenesis of the Fanconi syndrome is poorly understood, but a defect in cellular metabolism could be a unifying mechanism underlying its various aetiologies [12].

The exact mechanism(s) by which mitochondrial dysfunction can cause Fanconi syndrome and impaired LMWP uptake is unknown, although a number of steps in the endocytic pathway are thought to be ATP dependent. However, given the varied and important cellular roles of mitochondria apart from ATP synthesis [13], it is quite possible that abnormalities in mitochondrial function could affect endocytosis by non-ATP-mediated mechanisms. For example, mitochondria are significant generators of intracellular reactive oxygen species (ROS; mainly at RC complexes I and III [14]), which have been shown to be involved in endocytosis of membrane $\mathrm{Na} / \mathrm{K}$ ATPase in alveolar epithelial cells [15], and shear stressinduced fluid-phase endocytosis in vascular endothelial cells [16].

Opossum kidney $(\mathrm{OK})$ cells are an immortalised PT cell line - derived from the American opossum (Didelphys virginiana) - that form a polarised monolayer with tight junctions and a brush border [17]. OK cells have been used extensively as an in vitro model of the PT epithelium, and they take up LMWPs via receptor-mediated endocytosis [18]; indeed, the rate of LMWP uptake is thought to be greater than in other PT-derived cell lines. The expression of megalin and cubilin in OK cells has been shown previously [19]. Although not technically a LMWP, albumin is typically used for protein uptake experiments in OK cells, as it is endocytosed avidly, and it is an established ligand for the megalin-cubilin system [19]; uptake of albumin is thought to occur in the PT in vivo [20]. OK cells have also been used to study the uptake of dextrans by fluid-phase endocytosis [3], which may also contribute to LMWP uptake in the PT. Rotenone is a well-established inhibitor of complex I of the mitochondrial RC, and it is widely used in metabolic research.

By studying the effects of RC inhibitors (including rotenone) on albumin endocytosis, on ATP levels and on ROS production in OK cells in vitro, we wanted to investigate how mitochondrial dysfunction might impair LMWP uptake in the PT.

\section{Methods}

Materials

Magnesium green, cytosolically targeted luciferase and mitosox were all acquired from Molecular Probes (Invitrogen, Paisley, UK). All other reagents were obtained from Sigma-Aldrich (Poole, Dorset, UK), unless otherwise stated.

\section{Cell Culture}

OK cells were kindly provided by Dr. Alex Pearson (South West Thames Institute for Renal Research, Carshalton, UK). They were grown in DMEM:F12 supplemented with 5\% fetal bovine serum, but without antibiotics, and passaged every 6 days. For experiments, 13-mm-diameter sterile coverslips were coated with poly-L-lysine for $10 \mathrm{~min}$ (to assist cell adhesion); this was then washed off with sterile water and the coverslips were allowed to dry. Cells were seeded onto the coverslips in 24-well plates and grown until confluent (5-6 days).

\section{Cell Death Assay}

To establish whether or not OK cells were alive after exposure to RC inhibitors for $2 \mathrm{~h}$, cells were loaded with Hoechst (5 $\mu \mathrm{M}-$ excited at $720 \mathrm{~nm})$ and propidium iodide $(10 \mu \mathrm{M}$ - excited at 514 $\mathrm{nm}$ ). The former stains all cell nuclei, whereas the latter is normally excluded by an intact cell membrane, and stains the nuclei of permeablised and dead cells [21]. When assessing the specific toxicity of the glycolytic inhibitor 2-deoxyglucose (2-DG), pyruvate $(5 \mathrm{mM})$ was added to the solution as a substrate for oxidative phosphorylation.

\section{Endocytosis Assay}

FITC-labelled albumin (FA) was used as a ligand for receptormediated endocytosis by OK cells, as they are known to endocytose it avidly [3]. FITC-labelled dextran (FD) was used to investigate fluid-phase endocytosis (pinocytosis). For endocytosis experiments, OK cells were washed $4 \times$ in a HEPES-buffered solution ( $\mathrm{pH}$ 7.4) containing (in millimol/litre): $\mathrm{NaCl} \mathrm{138,} \mathrm{KCl} 5.6$, $\mathrm{NaHCO}_{3} 4.2, \mathrm{NaH}_{2} \mathrm{PO}_{4} 1.2, \mathrm{MgCl}_{2} 1.2, \mathrm{CaCl}_{2}$ 2.6, glucose 10 and HEPES 10. They were then incubated in HEPES-buffered solution ( $\mathrm{pH} 7.4)$ containing FA $(50 \mu \mathrm{g} / \mathrm{ml})$ or FD $(5 \mathrm{mg} / \mathrm{ml})$ for $1 \mathrm{~h}$ at $37^{\circ} \mathrm{C}$. The cells were then washed with $0.2 \mathrm{M}$ acetic acid/ $0.5 \mathrm{M} \mathrm{NaCl}$ to remove any FA bound to the external cell membrane, and then subsequently $6 \times$ with ice-cold HEPES-buffered solution to remove any FA or FD in solution and to prevent further endocytosis (which is temperature-dependent). The cells were fixed with $4 \%$ 
para-formaldehyde for $15 \mathrm{~min}$ and mounted on slides with Citifluor AF1 glycerol/phosphate-buffered saline mountant (Citifluor Ltd., London, UK), and imaged with a Zeiss LSM 510 inverted confocal microscope (Carl Zeiss Ltd., Welwyn Garden City, Hertfordshire, UK). Random fields were selected using the bright field setting and a $\times 40$ oil immersion objective; a $10-\mu \mathrm{m}$-deep image $\mathrm{z}$-stack (with 1- $\mu \mathrm{m}$ intervals) was imaged for each field at $488 \mathrm{~nm}$. The mean fluorescence signal collected for each stack was calculated with Zeiss LSM software with identical threshold values throughout.

The polarity of endocytosis in OK cells (i.e. apical versus basolateral uptake) was established by growing cells to confluence on Transwell plates (Appleton Woods, Birmingham, UK). FA was then applied to either the apical or basal side of the insert using the protocol above. Inserts were removed and mounted with Mowiol (a mountant that sets solid - a kind gift from Dr N. Carvou, UCL, UK) and imaged according to the same protocol as above.

To investigate the effects of mitochondrial RC inhibitors on the uptake of FA or FD in OK cells, rotenone $(10 \mu \mathrm{M})$, piericidin (10 $\mu \mathrm{M})$ or cyanide (1 mM) (all at supra-maximal concentrations) were added to the HEPES-buffered solution at the start of the 1-hour incubation to inhibit complex I (rotenone or piericidin) or IV (cyanide) of the RC; $5 \mathrm{~mm}$ of 2-DG was used (in the presence of $5 \mathrm{~mm}$ of pyruvate) to investigate the effect of inhibiting glycolysis.

\section{Dynamic Measurement of Intracellular ATP}

Two different methods were used to measure the effects of RC inhibition on cytosolic ATP levels in real time. The first involved the use of the fluorescent indicators magnesium green and tetramethyl rhodamine methyl ester (TMRM) to provide a dual readout of changes in ATP levels and mitochondrial membrane potential $\left(\Delta \psi_{\mathrm{m}}\right)$ [22]. The principle of this measurement is that cytosolic free $\left[\mathrm{Mg}^{2+}\right]$ rises as a consequence of ATP depletion. This occurs because ATP has a higher affinity for $\mathrm{Mg}^{2+}$ than ADP, and most $\mathrm{Mg}^{2+}$ in the cell is bound to ATP. Magnesium green fluorescence signal intensity changes in proportion to increases or decreases in $\left[\mathrm{Mg}^{2+}\right][22]$; therefore, the fluorescence signal changes inversely to changes in [ATP]. Meanwhile, alterations in the mitochondrial retention of TMRM represent changes in $\Delta \psi_{\mathrm{m}}$. Magnesium green was loaded at a concentration of $5 \mu \mathrm{M}$ with $0.01 \%$ pluronic (and $2.5 \mathrm{mM}$ of probenecid to prevent dye extrusion by organic anion transporters [23]) at $20^{\circ} \mathrm{C}$ for $20 \mathrm{~min}$. It was then washed off and the cells were incubated for a further $20 \mathrm{~min}$ with TMRM $50 \mathrm{nM}$ (and verapamil $100 \mu \mathrm{M}$ to prevent efflux of the drug by multidrug resistance transporters [24]). At this low concentration TMRM operates in the 'linear range' (i.e. fluorescence signal is proportional to dye concentration), and dye concentration reflects the Nernstian distribution between compartments according to local potential differences. Therefore, a reduction in $\Delta \psi_{\mathrm{m}}$ results in a decrease in mitochondrial specific TMRM fluorescence signal and a corresponding increase in cytosolic TMRM signal [25]. Magnesium green was excited at $488 \mathrm{~nm}$ and TMRM at $543 \mathrm{~nm}$; light was collected using $505-$ to $530-\mathrm{nm}$ band-pass and 560-nm long-pass filters, respectively. Much of the extra-nuclear volume of OK cells is filled with mitochondria; to obtain a 'cytosolic' signal for recording simultaneous changes in magnesium green and TMRM, regions of interest (ROIs) within the nuclei of cells were used for analysis.
The second method applied for measuring changes in ATP levels was a luciferin-luciferase assay; alterations in luminescence were recorded using a custom-built luminometer (Cairn Research, Faversham, Kent, UK). OK cells were tansfected with luciferase targeted to the cytosol. Cells were perfused with HEPESbuffered solution and supplemented with $50 \mu \mathrm{M}$ of luciferin (Promega Ltd., Southampton, UK). For both ATP assay methods the $\mathrm{RC}$ inhibitor rotenone $(10 \mu \mathrm{M})$ and the glycolysis inhibitor iodoacetic acid (IAA - $1 \mathrm{mM}$ ) were added sequentially to investigate their effects.

\section{Measurement of ROS Production}

To measure mitochondrial ROS production, OK cells were loaded with the superoxide-sensitive dye mitosox (5 $\mu \mathrm{M})$, which localizes to mitochondria. The rate of increase in fluorescence signal is proportional to the rate of ROS production. The cells were incubated with the dye for $10 \mathrm{~min}$ at room temperature before imaging. Mitosox was excited at $543 \mathrm{~nm}$ and light was collected using a 560- to $615-\mathrm{nm}$ band-pass filter. Images were acquired every $2 \mathrm{~min}$ to minimize laser-induced photo-toxicity. After a 10 -min control period, the RC inhibitors rotenone $(10 \mu \mathrm{M})$, piericidin $(10 \mu \mathrm{M})$ or cyanide $(1 \mathrm{mM})$ were added. ROIs were drawn around areas of cells with high mitochondrial density.

\section{Electron Microscopy of OK Cell Structure}

To perform electron microscopy, OK cells were grown on melinex polyester film until a confluent monolayer had been formed (5-7 days). The cells were then exposed to rotenone $(10 \mu \mathrm{M})$ in a HEPES-buffered solution (see 'Endocytosis Assay') for $1 \mathrm{~h}$ at $37^{\circ} \mathrm{C}$. At the end of the experiment, the drug was washed off and primary fixation was performed in $1 \%$ paraformaldehyde $/ 1.5 \%$ glutaraldehyde in phosphate-buffered solution (PBS). Following a wash with PBS, secondary fixation was performed using $1 \%$ osmium tetroxide $1.5 \%$ potassium ferricyanide in PBS. The cells were then thoroughly washed with distilled water, followed by dehydration through graded ethanol (30, 50, 70, 90 and 100\%); they were infiltrated with a 50:50 mixture of 100\% ethanol/epoxy resin (Lemix, TAAB Laboratories Equipment Ltd., Aldermaston, $\mathrm{UK}$ ) and finally an overnight infiltration was performed with $100 \%$ resin.

Pieces of the melinex were then flat embedded with the cells face up in liquid resin. These were polymerized at $70^{\circ} \mathrm{C}$ overnight, and the melinex was then stripped away from the cells leaving them embedded in the resin. The resin blocks were trimmed down and a secondary embedding was carried out with the cells face up. Using a Reichert Ultracut E ultramicrotome, semi-thin sections were cut with glass knives and stained with toluidine blue. Ultra-thin sections were cut with a diamond knife picked up on copper grids and stained with uranyl acetate and Reynold's lead citrate. The grids were viewed with a Philips CM120 transmission electron microscope and digital images collected with an AMT digital camera.

\section{Statistical Analysis}

The results are presented as means \pm SEM. One-way analysis of variance was used to investigate statistical differences among the study groups. Where differences were found, individual groups were compared by an unpaired t test. A p value of $<0.05$ was taken as significant. 


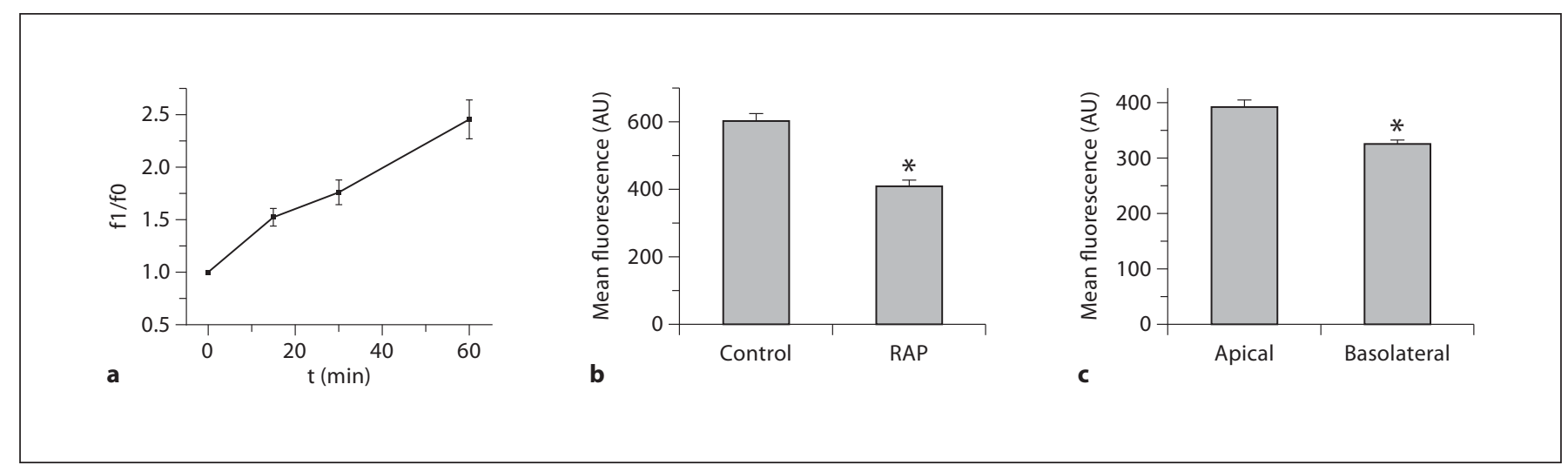

Fig. 1. a Mechanism and polarity of FITC-albumin uptake in OK cells. OK cells endocytose FITC-albumin progressively over $1 \mathrm{~h}$. b Uptake is partly megalin-mediated, as demonstrated by a reduced fluorescence signal after $1 \mathrm{~h}$ in the presence of the megalin receptor inhibitor receptor-associated protein (RAP). c Experiments performed on OK cells grown on transwell inserts revealed that apical uptake was greater than basolateral uptake. Values given are mean fluorescence $( \pm$ SE) per $\times 40$ objective field (a and $\mathbf{b}: \mathbf{n}=15, \mathbf{c}: \mathrm{n}=10) .{ }^{*} \mathrm{p}<0.005$.

\section{Results}

Megalin-Mediated FITC-Albumin Endocytosis in OK Cells Occurs Predominantly at the Apical Border

OK cells form a confluent monolayer when grown in normal culture conditions: they endocytose FA when incubated at $37^{\circ} \mathrm{C}$, which can be measured as a progressive increase in fluorescence signal over $1 \mathrm{~h}$ (fig. 1a). This uptake was, at least in part, mediated by the megalin receptor, as it was inhibited by receptor-associated protein, an established inhibitor of megalin-mediated endocytosis [19] (fig. 1b). To assess the polarity of FA uptake, OK cells were grown on Transwell inserts until confluent. Significantly greater uptake of FA was observed after 1 hour when FA was applied to the apical membrane than when applied to the basolateral membrane (fig. 1c). This is consistent with the situation in the PT in vivo, where LMWP endocytosis is thought to occur mainly at the apical membrane. From here on, endocytosis experiments were performed with OK cells grown as monolayers on coverslips, where the cell membrane exposed to ligands is predominantly apical.

\section{RC Inhibition Does Not Cause Significant Necrosis in OK Cells}

To ensure that exposure of OK cells to inhibitors of the mitochondrial RC does not result in rapid necrotic cell death within the time period of the endocytosis assay, a standard Hoechst/propidium iodide assay was performed. After $2 \mathrm{~h}$ (twice the length of the endocytosis as- say period) the proportion of dead cells observed compared with the control $(0.17 \% \pm 0.17$ per $\times 40$ objective field, $\mathrm{n}=5$ ) was not significantly increased following incubation with rotenone $(10 \mu \mathrm{M})(2.39 \% \pm 0.73, \mathrm{n}=5$, $\mathrm{p}>0.9)$, cyanide $(1 \mathrm{mM})(0.20 \% \pm 0.20, \mathrm{n}=5, \mathrm{p}>0.9)$ or $2-D G(5 \mathrm{mM})(1.62 \% \pm 0.50, \mathrm{n}=5, \mathrm{p}>0.9)$ (fig. $2 \mathrm{a})$.

\section{RC Inhibition Does Not Alter Total FITC-Albumin Uptake in OK Cells}

The control fluorescence signal emitted by OK cells per $\times 40$ objective field (assigned the value of $100 \%$ ) after incubation for $1 \mathrm{~h}$ at $37^{\circ} \mathrm{C}$ with FA was reduced by a small amount by incubation with the RC inhibitors rotenone $(10 \mu \mathrm{M})(92.8 \%$ of control signal $\pm 2.4, \mathrm{n}=20)$, piericidin $(10 \mu \mathrm{M})(89.5 \% \pm 2.0, \mathrm{n}=20)$ or cyanide $(1 \mathrm{mM})(93.7 \%$ $\pm 1.8, \mathrm{n}=20$ ) (fig. $2 \mathrm{~b}$ ), although only the results obtained with piericidin achieved statistical significance $(\mathrm{p}<0.05)$. This shows that inhibition of the RC in OK cells has little or no effect on receptor-mediated endocytosis at the apical membrane in OK cells. However, incubation with 2-DG (5 mM) produced a large and significant decrease in fluorescence signal ( $51.6 \%$ of control signal $\pm 1.7, \mathrm{n}=$ $15, \mathrm{p}<0.001$ ), demonstrating that blockade of glycolysis in this cell model causes a far more potent inhibition of endocytosis than RC inhibition.

\section{Cytosolic ATP Levels Are Maintained Predominantly} by Anaerobic Metabolism in OK Cells

To investigate why blockade of glycolysis had a much greater inhibitory effect on FA uptake than RC inhibition, 


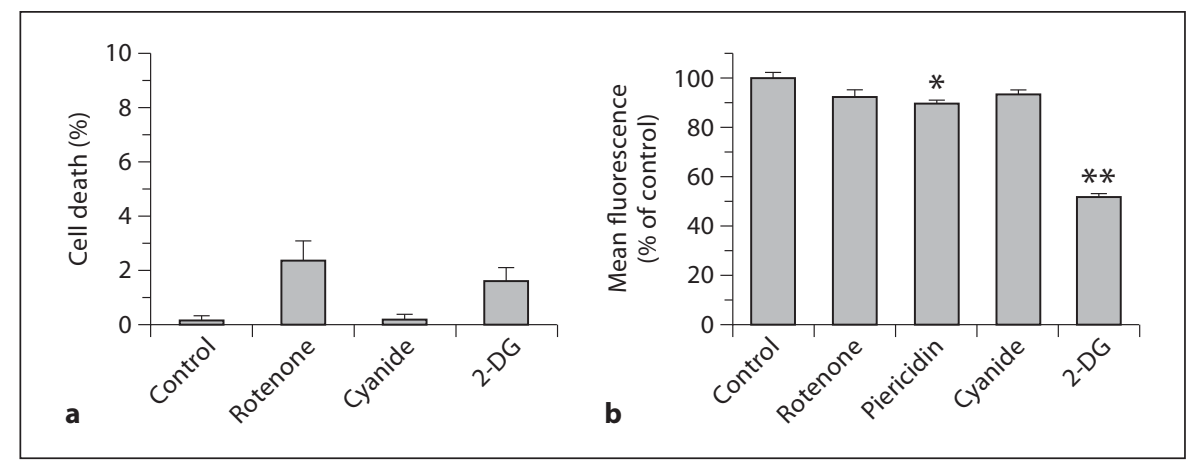

Fig. 2. a The effect of RC inhibition on cell death and total FITCalbumin uptake in OK cells. Necrotic cell death in OK cells was measured using a Hoechst/propidium iodide assay. There was no significant increase compared with control in the percentage of dead cells after $2 \mathrm{~h}$ of incubation at $37^{\circ} \mathrm{C}$ with rotenone $(10 \mu \mathrm{M})$, cyanide (1 mM) or 2-DG (5 mM). Values given are mean percentage $( \pm S E)$ of propidium-iodide-positive cells per $\times 40$ objective field $(\mathrm{n}=5)$. $\mathbf{b}$ Uptake of FITC-albumin in OK cells over $1 \mathrm{~h}$ at $37^{\circ} \mathrm{C}$ was inhibited by a small, but significant, amount by the RC inhibitor piericidin $(10 \mu \mathrm{M})$. No significant decrease was observed with rotenone $(10 \mu \mathrm{M})$ or cyanide $(1 \mathrm{mM})$. 2-DG $(5 \mathrm{mM})$ caused a much larger impairment of FITC-albumin uptake. Values given are mean fluorescence $( \pm$ SE) per $\times 40$ objective field $[n=20$ for all experiments, except $2-\mathrm{DG}(\mathrm{n}=15)] .{ }^{*} \mathrm{p}<0.05,{ }^{* *} \mathrm{p}<0.001$.

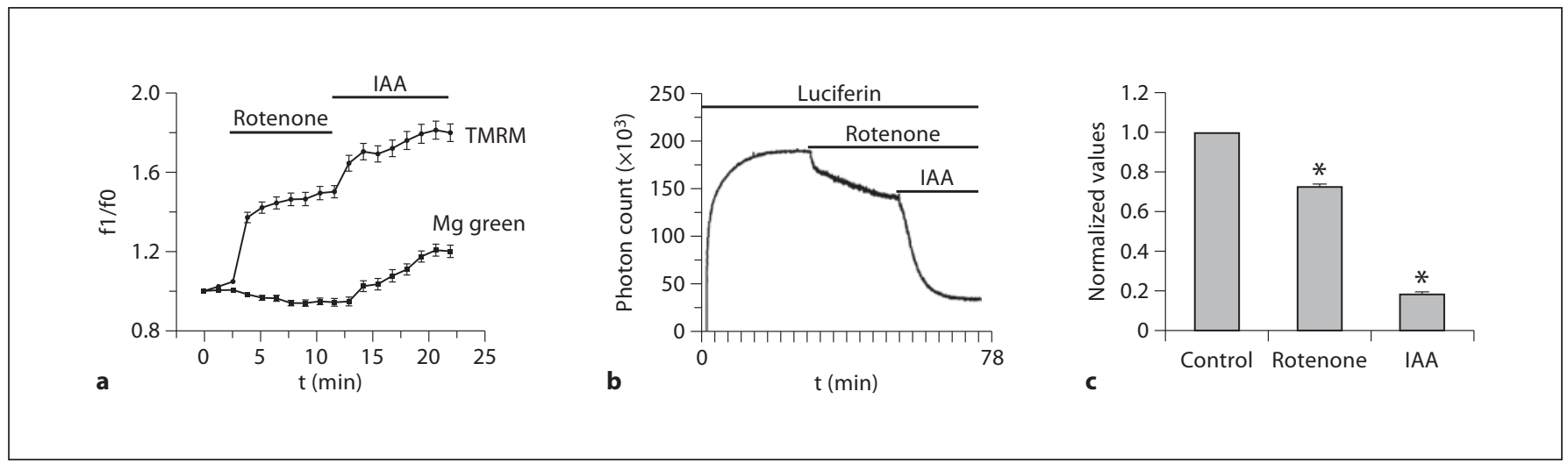

Fig. 3. The effect of RC inhibition on cytosolic ATP levels in OK cells. a Rotenone $(10 \mu \mathrm{M})$ caused an increase in cytosolic TMRM signal, consistent with inhibition of the RC and depolarisation of $\Delta \psi_{\mathrm{m}}$. However, IAA (1 mM) had a much greater effect on magnesium green (Mg green) signal than rotenone, implying that cytosolic ATP is predominantly derived from anaerobic metabolism in OK cells. Values given are mean nuclear fluorescence signal ( \pm SE) from a total of 154 (TMRM) and 126 (Mg green) cells. To corroborate these findings using a different technique for measuring cytosolic ATP levels, OK cells were transfected with lucif- erase targeted to the cytosol (Cyt-Luc). Cells emitted a luminescence signal following the addition of luciferin $(50 \mu \mathrm{M})$, the intensity of which is ATP dependent. b A representative trace is depicted, showing that $\mathrm{RC}$ inhibition with rotenone $(10 \mu \mathrm{M})$ produced only a small decrease in signal intensity, while a much larger decrease occurred following blockade of glycolysis with IAA $(1 \mathrm{mM})$. c Mean normalized values $( \pm \mathrm{SE})(1=$ maximum signal after luciferin and $0=$ zero counts) from 11 experiments are given. ${ }^{*} \mathrm{p}<0.01$. we compared the relative dependence of ATP generation on aerobic versus anaerobic metabolism in OK cells. OK cells were loaded with the fluorescent dye magnesium green; intracellular free magnesium concentration (and so the magnesium green fluorescence signal) changes inversely in response to changes in cytosolic ATP levels. The cells were simultaneously loaded with TMRM, to provide a measure of $\Delta \psi_{\mathrm{m}}$, and changes in the cytosolic signal were measured to monitor the redistribution of TMRM from mitochondria to cytosol in response to falling $\Delta \psi_{\mathrm{m}}$.

Inhibition of the RC with rotenone $(10 \mu \mathrm{M})$ did not change the magnesium green signal, suggesting a mini- 
mal effect on the cytosolic ATP level (fig. 3a). However, rotenone did cause a rise in the cytosolic TMRM signal (fig. 3a), consistent with depolarisation of $\Delta \psi_{\mathrm{m}}$, and redistribution of the dye from the mitochondria to the cytosol. This change provided a positive control and indicated that the drug was having its expected effect (i.e. inhibiting RC activity). In response to subsequent inhibition of glycolysis with IAA (1 mM), the magnesium green signal increased, indicating a fall in cytosolic ATP levels. IAA caused an additional rise in the TMRM signal, consistent with further depolarization of $\Delta \psi_{\mathrm{m}}$. This reflects the dependence of $\Delta \psi_{\mathrm{m}}$ on the 'reverse' activity of the $\mathrm{F}_{1} \mathrm{~F}_{\mathrm{O}}$-ATPase, which is maintained by the hydrolysis of glycolytic ATP when the RC is blocked [26].

To corroborate the data obtained with magnesium green/TMRM, the effect of RC inhibition on cytosolic ATP levels was also investigated using a luciferin-luciferase assay. Addition of luciferin to OK cells transfected with luciferase targeted to the cytosol produced a large rise in luminescence, reflecting high transfection efficiency (fig. 3bi). Addition of rotenone $(10 \mu \mathrm{M})$ caused only a small decrease in luminescence signal to a normalised luminescence value of $0.735 \pm 0.009$ (where $1=$ maximal signal after luciferin and $0=$ zero counts, $\mathrm{p}<$ 0.01 ) (fig. 3bii). Following addition of IAA $(1 \mathrm{~mm})$, the normalised luminescence fell to just $0.185 \pm 0.003$ ( $\mathrm{n}=$ 11 experiments, $\mathrm{p}<0.01$ ), suggesting almost complete depletion of ATP.

Taken together these results suggest that the OK cells are predominantly dependent on anaerobic glycolysis for ATP production and that RC inhibition has little effect on cytosolic ATP levels, which might explain the small effect of RC inhibition on FA uptake in OK cells.

\section{Rotenone Alters the Pattern of FITC-Albumin Uptake in OK Cells}

When imaging the uptake of FA in OK cells it was noted that while there was very little difference between the various RC inhibitors in their effect on total uptake, there was a marked difference in the pattern of uptake, particularly for rotenone. Neither piericidin $(10 \mu \mathrm{M})$, another inhibitor of complex I, nor cyanide ( $1 \mathrm{mM}$ ) changed the control pattern of FA uptake; however, a striking difference was observed in the presence of rotenone $(10 \mu \mathrm{M})$ (fig. 4a). The effects of rotenone on the pattern of FA uptake were unlikely to be due to an impairment of substrate utilization at complex I because piericidin did not have the same effect. Furthermore, bypassing the inhibition of electron flow at complex I with the addition of the complex II substrate methyl-succinate $(5 \mathrm{mM}$ ) (which should restore normal RC function and ATP production) did not affect the uptake pattern observed with rotenone.

For fluid-phase endocytosis the control pattern of uptake of FD was similar to FA; the majority of FD appearing in the vicinity of the apical brush border (fig. 4a). Rotenone $(10 \mu \mathrm{M})$ also affected the pattern of uptake of $\mathrm{FD}$, similar to its effects on FA uptake. This suggests that the striking effects of rotenone on FA uptake are probably due to widespread structural changes within the cell that disrupt the uptake machinery, rather than a specific or direct effect on megalin/cubulin receptor-mediated endocytosis.

Fig. 4. a The effects of rotenone on the pattern of uptake of FITCalbumin/FITC-dextran, ROS production and cell structure. The control pattern of uptake of FITC-albumin in OK cells was markedly altered by exposure to the RC inhibitor rotenone $(10 \mu \mathrm{M})$ but was not affected by exposure to another complex I inhibitor, piericidin $(10 \mu \mathrm{M})$, nor by the complex IV inhibitor cyanide (1 mM). The pattern of FITC-albumin uptake observed in the presence of rotenone was not altered by incubation with either the RC complex II substrate methyl-succinate $(5 \mathrm{mM})$ (which will bypass inhibition at complex I) or the anti-oxidant MnTBAP (50 $\mu \mathrm{M})$. Images shown are representative $\times 63$ objective fields of $\mathrm{OK}$ cells incubated with FITC-albumin or FITC-dextran at $37^{\circ} \mathrm{C}$ for $1 \mathrm{~h}$. b Mitochondrial ROS production in OK cells was measured using the dye mitosox; the rate of change of fluorescence signal was taken to be proportional to the rate of ROS production. Rotenone $(10 \mu \mathrm{M})$ caused a significant increase in the rate of ROS production compared with the control. However, this increase was obliterated by the anti-oxidant MnTBAP $(50 \mu \mathrm{M})$. No significant difference from the control rate of production was observed after addition of piericidin $(10 \mu \mathrm{M})$, while cyanide $(1 \mathrm{mM})$ significantly decreased this rate. Values given are mean rates of change in fluorescence signal per ROI, expressed as a percentage of the control rate $( \pm$ SE) from 163 cells (rotenone), 225 cells (rotenone + MnTBAP), 218 cells (piericidin) and 140 cells (cyanide). ${ }^{*} \mathrm{p}<$ 0.001 compared to control. c An uptake pattern of FITC-albumin similar to that caused by rotenone was observed in OK cells following exposure to colchicine $(10 \mu \mathrm{M})$, an inhibitor of microtubule assembly. In cells exposed to rotenone $(10 \mu \mathrm{M})$, the control pattern of FITC-albumin uptake was restored by the presence of taxol $(10 \mu \mathrm{M})$, a microtubule-stabilising agent. Representative images are depicted of single OK cells (scale bar $=2 \mu \mathrm{m}$ ) and $\times 63$ objective fields (scale bar $=20 \mu \mathrm{m}$ ) following incubation with FITC-albumin at $37^{\circ} \mathrm{C}$ for $1 \mathrm{~h}$. Rotenone also caused an abnormal pattern of FITC-dextran uptake, demonstrating that the effects applied to fluid phase as well as receptor-mediated endocytosis. d Electron micrographs of OK cells confirm that the cells form a confluent monolayer in culture, with an apical brush border (BB). Following exposure to rotenone $(10 \mu \mathrm{M})$ for $1 \mathrm{~h}$, extensive structural damage was observed in the cells with loss of the brush border and the appearance of numerous vacuoles (V) and abnormally shaped mitochondria (M). 


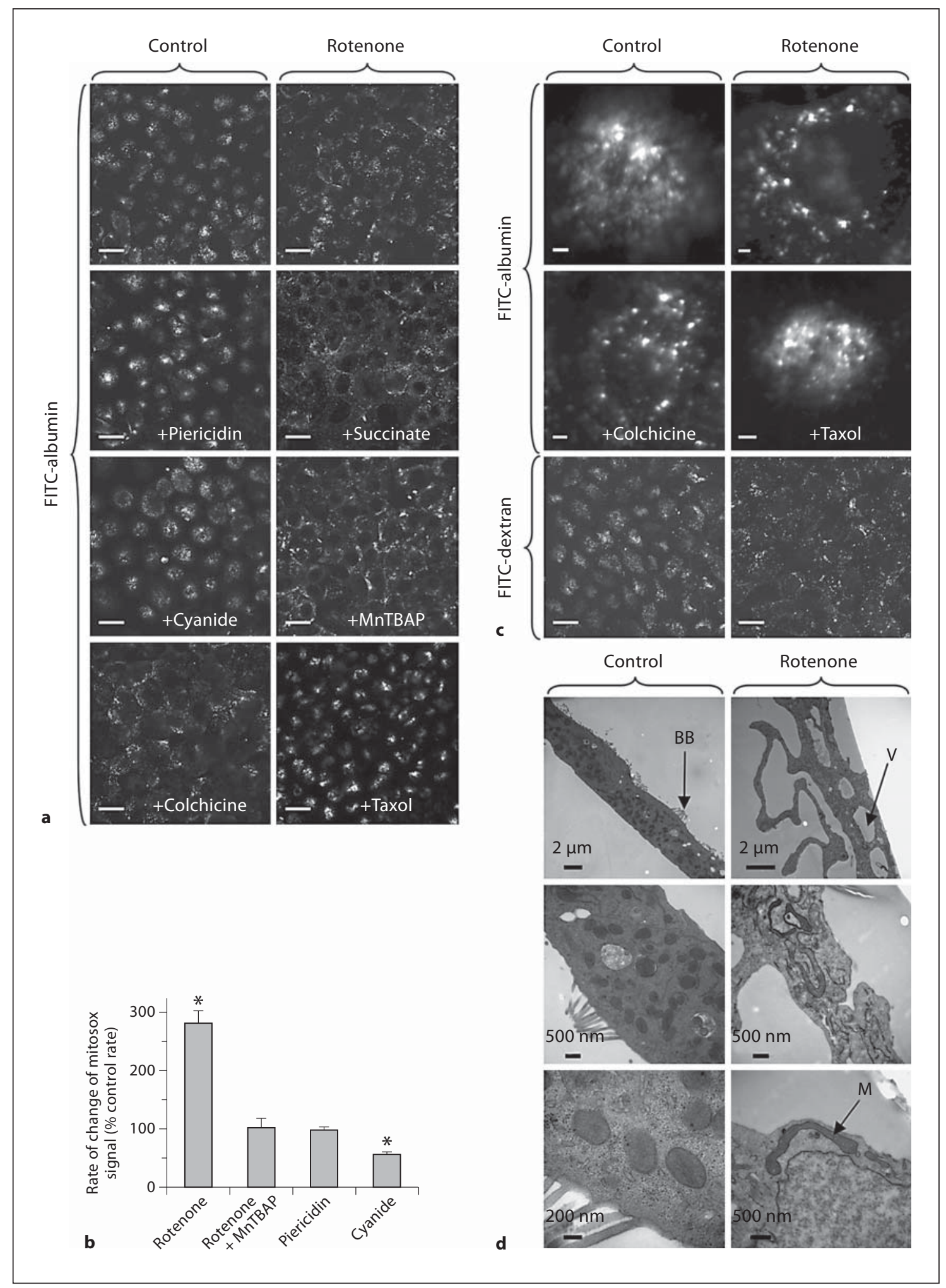




\section{Rotenone Causes a Greater Increase in ROS}

\section{Production in OK Cells than Other RC Inhibitors}

We postulated that the effects of rotenone may have been due to excess ROS production, since complex I is a potent site of ROS generation in mitochondria. However, the anti-oxidant Mn (III) tetrakis (4-benzoic acid) porphyrin (MnTBAP - $50 \mu \mathrm{M}$ ) had no effect on the pattern of FA uptake seen with rotenone (fig. 4a).

As a positive control to ensure that $50 \mu \mathrm{M}$ of MnTBAP was sufficient to prevent any rise in ROS production caused by rotenone, we measured mitochondrial ROS production in OK cells by loading them with the ROSsensitive dye mitosox, a mitochondrially targeted derivative of hydroethidium. The mitochondrial localisation of the mitosox signal was evident, and the fluorescence signal increased progressively with time; the rate of increase was taken to be proportional to the rate of ROS production. Rotenone $(10 \mu \mathrm{M})$ caused a significant increase in the rate of change of mitosox signal (rate after rotenone $=282 \pm 21 \%$ of the control rate, $\mathrm{n}=163$ cells, $\mathrm{p}<0.001$ ) (fig. $4 \mathrm{~b}$ ). This was prevented by $50 \mu \mathrm{M}$ MnTBAP (rate post rotenone and MnTBAP $103 \pm 16 \%$ of the control rate, $\mathrm{n}=225$ cells). Thus, $50 \mu \mathrm{M}$ of MnTBAP completely prevents the increase in ROS production seen in response to rotenone, but does not alter the effect of rotenone on intracellular FA distribution, suggesting that the effects of rotenone on the pattern of FA uptake in OK cells were not mediated by ROS. The rate of change of mitosox signal was not significantly increased by piericidin (10 $\mu \mathrm{M})(99 \pm 4 \%$ of the control rate, $\mathrm{n}=218$ cells, $\mathrm{p}>0.9$ ), another RC complex I inhibitor, implying that rotenoneinduced ROS production depends on the site of action of this drug at complex I. The rate of change in mitosox signal was significantly decreased by cyanide $(1 \mathrm{mM})(57 \pm$ $5 \%$ of control rate, $n=140$ cells, $p<0.001$ ), indicating that blockade of RC at complex IV lowers the rate of ROS production in OK cells.

Rotenone Has Toxic Structural Effects in OK Cells due to Inhibition of Microtubule Proliferation

Since neither methyl-succinate nor MnTBAP prevented the effects of rotenone on the pattern of FA endocytosis, and the RC inhibitors piericidin and cyanide did not produce the same changes as rotenone, we wondered if the effect of rotenone on endocytosis was extra-mitochondrial. There are published data suggesting that rotenone can depolymerise microtubules [27-29], in addition to its effects on the RC. Colchicine is an established inhibitor of microtubule polymerisation. A pattern of FA uptake similar to that observed with rotenone was seen in response to colchicine $(10 \mu \mathrm{M})$; furthermore, co-incubation with the microtubule-stabilising agent taxol (10 $\mu \mathrm{M})$ with rotenone $(10 \mu \mathrm{M})$ produced a pattern of FA uptake similar to control (fig. 4c). These results suggest that the effects of rotenone on the pattern of FA uptake in OK cells are due to inhibition of microtubule polymerisation.

The structural effects of rotenone on OK cells were investigated further by electron microscopy. Control images showed that OK cells form a confluent polarised monolayer in culture with an apical brush border (fig. 4d), which is clearly visible, but not as well developed as the native PT brush border in vivo. Addition of rotenone (10 $\mu \mathrm{M})$ caused widespread structural damage, including loss of the brush border and the appearance of numerous large vacuoles, and abnormally shaped and swollen mitochondria.

\section{Discussion}

Inhibition of the mitochondrial RC in OK cells produced little or no effect on the total uptake of FA, which is perhaps surprising given the seeming vulnerability of the PT to mitochondrial dysfunction in vivo. Several clinical observations support a role for mitochondrial dysfunction in the pathogenesis of the renal Fanconi syndrome: (1) the typical renal presentation of children with mitochondrial cytopathy is Fanconi syndrome [5, 30]; (2) drugs known to be toxic to mitochondria (including antiretroviral therapy) can cause reversible Fanconi syndrome [31]; (3) Fanconi syndrome has been reported in primary biliary cirrhosis, a condition characterized by the presence of anti-mitochondrial antibodies [32]; (4) the toxic metabolites that accumulate in cystinosis [33] and tyrosinaemia [34] (both established causes of Fanconi syndrome) inhibit complex I of the RC in vitro; (5) blockade of the RC inhibits sodium and phosphate transport in isolated rabbit PT [35], and cystine loading (an in vitro model of cystinosis) leads to ATP depletion and impaired fluid reabsorption [36]. However, unlike the native PT, we have shown that OK cells have a significant capacity to generate ATP anaerobically, which probably explains their resistance to $\mathrm{RC}$ inhibition.

Immortalised cells in culture tend to become increasingly anaerobic with time [37], as is true of many cancer cells (the Warburg effect [38]). Accordingly, blockade of glycolysis in OK cells produced a larger decrease in cytosolic ATP levels than RC inhibition and also inhibited FA uptake to a greater extent, suggesting that ATP might play an important role in receptor-mediated endocytosis 
in the PT. A previous study investigating the effects of metabolic inhibitors on fluid-phase endocytosis in OK cells also reported that IAA caused a bigger drop in ATP levels than cyanide, consistent with our findings [39]. IAA is an alkylating agent that interacts with thiol groups on proteins and, therefore, may have effects on enzyme systems other than glycolysis [40]; nevertheless, this does not detract from the finding that RC blockade had only a relatively small effect on ATP concentration.

Previous studies of both renal and non-renal cell lines indicate that a change in cytosolic ATP level can have a significant effect on receptor-mediated endocytosis. The endocytosis and recycling of transferrin and its associated receptor in the MDCK renal cell line, which is more distal nephron-like in its properties, was found to be dependent on ATP levels [41]; furthermore, uptake of radiolabelled transferrin in both K562 and Hela cells can be inhibited by ATP depletion [42]. In the Cos-7 cell line the chloride channel CIC-2 is upregulated at the cell membrane following ATP depletion, which decreases endocytic retrieval of the channel from the plasma membrane [43]. Similarly, in human astrocytoma cells (1321N1), endocytic downregulation of $\beta$-adrenergic receptors in response to catecholamines is ATP-dependent [44].

Several intracellular mechanisms involved in the process of endocytosis are thought to require ATP, such as the exchange of free and bound clathrin in clathrin-coated pits [45]. An intact actin cytoskeleton is important for endocytosis [46], and actin polymerisation is ATP dependent (ATP bound to monomeric [G] actin undergoes hydrolysis when polymeric [F] actin is formed [47]). Trafficking of endocytotic vesicles along microtubules by the motor proteins kinesin and dynein also requires ATP [48]. In addition, for receptor recycling, dissociation of receptor and ligand inside endosomes must occur, a process that requires acidification via an ATP-dependent proton pump and chloride/proton antiporter [49-51]. Disruption of this acidification process leads to impaired protein endocytosis [52].

To get around the problem of immortalised cell lines becoming anaerobic, strategies have been adopted to encourage a switch to aerobic metabolism. The methods tried have included shaking culture flasks to increase aeration and lowering culture medium glucose concentration to reduce the drive toward glycolysis [53]. However, it is unclear how successful these approaches are. An alternative manoeuvre is to use primary cell cultures, although freshly isolated PT cells tend to lose their phenotype within a few passages. Direct visualisation of LMWP endocytosis in the $\mathrm{PT}$ is now possible in vivo using multi- photon microscopy [54], but this is a technically demanding approach.

To investigate other potential mediators of the effects of RC inhibition on endocytosis (apart from changes in ATP levels), we measured the effects of RC inhibitors on mitochondrial ROS production in OK cells. Inhibiting the RC with piericidin did not lead to a significant increase in ROS production, while cyanide decreased ROS production. An earlier investigation of the effects of cyanide on ROS production in another renal cell line, LLCMK2, reported an increase in ROS production and oxidative stress [55]. However, cyanide exposure was much longer $(4 \mathrm{~h})$ and the dye used to measure ROS (dichlorofluorescein) is not specific to mitochondrial ROS production. This paper also reported a significant decrease in cytosolic ATP levels in response to cyanide, suggesting a much greater dependence of LLC-MK2 cells on aerobic metabolism compared with OK cells. From a metabolic standpoint, LLC-MK2 cells seem a more physiological model of PT cells in vivo. However, they exhibit a limited capacity for albumin endocytosis when compared with OK cells.

In contrast to piericidin, inhibition of complex I with rotenone produced a large increase in ROS production. Differences between rotenone and piericidin in ROS generation at RC complex I have been reported before [56], although both are thought to share a common binding domain with overlapping sites [57], differences in the effects of the two reagents may result from different conformational changes induced in the complex on binding either reagent [58]. Much still remains to be done to elucidate the behaviour of complex I and the mechanisms of ROS generation at this site, particularly in different tissues.

Rotenone had marked structural effects on OK cells, causing widespread cellular damage and leading to an altered pattern of both FA and FD uptake. Rotenone is a much used reagent, both as an experimental inhibitor of complex I of the RC and as a commercial pesticide. It is thought to block the electron flow at the ubiquinonebinding site of complex I, leading to an increased NADH/ $\mathrm{NAD}^{+}$ratio at the 'upstream' flavin-binding site, which favours increased ROS production [59]. Another (and less well-known extra-mitochondrial) effect of rotenone is inhibition of microtubule polymerization [27]. The similar effects of rotenone and colchicine on FA uptake in OK cells suggests that rotenone's toxicity is due to microtubule inhibition. This is also consistent with the protective effect of the microtubule-stabilising agent taxol. Microtubules are part of the cell cytoskeleton and are impor- 
tant in trafficking ion transport proteins in polarised cells to the appropriate cell membrane [60]. Injection of colchicine in rats causes significant structural abnormalities in the PT on electron microscopy [61], and inhibition of microtubule polymerisation has been reported previously to reduce albumin uptake in OK cells [46].

In summary, in spite of their widespread use as an in vitro cell model of LMWP uptake in the PT, OK cells are very different metabolically from native PT in vivo; although they show avid and consistent endocytosis of albumin, the underlying mechanisms might not accurately model those occurring in vivo. This may be important, because our results suggest that FA uptake in OK cells is
ATP-dependent. Moreover, rotenone should be used with caution in cell culture studies of mitochondrial function, since it causes a much greater increase in mitochondrial superoxide production than either piericidin or cyanide, and it has significant extra-mitochondrial effects on microtubule polymerisation.

\section{Acknowledgements}

The authors are grateful for assistance from the Division of Medicine, UCL. This work was supported by grants from Kidney Research UK and the Wellcome Trust. M.C. was supported by a Marie Curie-Intra-European Fellowship.

\section{References}

1 Christensen EI, Gburek J: Protein reabsorption in renal proximal tubule-function and dysfunction in kidney pathophysiology. Pediatr Nephrol 2004;19:714-721.

2 Verroust PJ, Birn H, Nielsen R, Kozyraki R, Christensen EI: The tandem endocytic receptors megalin and cubilin are important proteins in renal pathology. Kidney Int 2002; 62:745-756.

-3 Gekle M, Mildenberger S, Freudinger R, Silbernagl S: Endosomal alkalinization reduces Jmax and $\mathrm{Km}$ of albumin receptor-mediated endocytosis in OK cells. Am J Physiol 1995; 268:F899-F906.

4 Rich PR: The molecular machinery of Keilin's respiratory chain. Biochem Soc Trans 2003;31:1095-1105.

5 Niaudet P, Rotig A: Renal involvement in mitochondrial cytopathies. Pediatr Nephrol 1996; 10:368-373.

6 Izzedine H, Launay-Vacher V, Deray G: Antiviral drug-induced nephrotoxicity. Am J Kidney Dis 2005;45:804-817.

7 Izzedine H, Launay-Vacher V, Deray G: Fanconi syndrome associated with didanosine therapy. AIDS 2005;19:844-845.

-8 Shanley PF, Rosen MD, Brezis M, Silva P, Epstein FH, Rosen S: Topography of focal proximal tubular necrosis after ischemia with reflow in the rat kidney. Am J Pathol 1986;122: 462-468.

\9 Bagnasco S, Good D, Balaban R, Burg M: Lactate production in isolated segments of the rat nephron. Am J Physiol 1985;248:F522F526.

10 Hall AM, Unwin RJ, Parker N, Duchen MR: Multiphoton imaging reveals differences in mitochondrial function between nephron segments. J Am Soc Nephrol 2009;20:12931302.
11 Hall AM, Kleta R, Unwin RJ: The Renal Fanconi Syndrome; in Barrat J, Harris K, Topham P (eds): Oxford Desk Reference in Nephrology. New York, Oxford University Press, 2009.

12 Hall AM, Unwin RJ: The not so 'mighty chondrion': emergence of renal diseases due to mitochondrial dysfunction. Nephron Physiol 2007;105:1-10.

13 Duchen MR: Mitochondria in health and disease: perspectives on a new mitochondrial biology. Mol Aspects Med 2004;25:365451.

14 Murphy MP: How mitochondria produce reactive oxygen species. Biochem J 2009;417: 1-13.

15 Dada LA, Chandel NS, Ridge KM, Pedemonte C, Bertorello AM, Sznajder JI: Hypoxiainduced endocytosis of Na,K-ATPase in alveolar epithelial cells is mediated by mitochondrial reactive oxygen species and PKC$\zeta$. J Clin Invest 2003;111:1057-1064.

16 Niwa K, Sakai J, Karino T, Aonuma H, Watanabe T, Ohyama T, Inanami O, Kuwabara M: Reactive oxygen species mediate shear stress-induced fluid-phase endocytosis in vascular endothelial cells. Free Radic Res 2006;40:167-174.

17 Rabkin R, Yagil C, Frank B: Basolateral and apical binding, internalization, and degradation of insulin by cultured kidney epithelial cells. Am J Physiol 1989;257:E895-E902.

18 Sidaway JE, Davidson RG, McTaggart F, Orton TC, Scott RC, Smith GJ, Brunskill NJ: Inhibitors of 3-hydroxy-3-methylglutaryl$\mathrm{CoA}$ reductase reduce receptor-mediated endocytosis in opossum kidney cells. J Am Soc Nephrol 2004; 15:2258-2265.
19 Zhai XY, Nielsen R, Birn H, Drumm K, Mildenberger S, Freudinger R, Moestrup SK, Verroust PJ, Christensen EI, Gekle M: Cubilin- and megalin-mediated uptake of albumin in cultured proximal tubule cells of opossum kidney. Kidney Int 2000;58:15231533.

20 Thakkar H, Lowe PA, Price CP, Newman DJ: Measurement of the kinetics of protein uptake by proximal tubular cells using an optical biosensor. Kidney Int 1998;54:1197-1205.

21 Ciancio G, Pollack A, Taupier MA, Block NL, Irvin GL III: Measurement of cell-cycle phase-specific cell death using Hoechst 33342 and propidium iodide: preservation by ethanol fixation. J Histochem Cytochem 1988;36:1147-1152.

22 Leyssens A, Nowicky AV, Patterson L, Crompton M, Duchen MR: The relationship between mitochondrial state, ATP hydrolysis, $[\mathrm{Mg} 2+] \mathrm{i}$ and $[\mathrm{Ca} 2+] \mathrm{i}$ studied in isolated rat cardiomyocytes. J Physiol 1996;496:111128.

23 Miller DS, Letcher S, Barnes DM: Fluorescence imaging study of organic anion transport from renal proximal tubule cell to lumen. Am J Physiol 1996;271:F508-F520.

24 Neyfakh AA: Use of fluorescent dyes as molecular probes for the study of multidrug resistance. Exp Cell Res 1988;174:168-176.

25 Duchen MR, Surin A, Jacobson J: Imaging mitochondrial function in intact cells. Methods Enzymol 2003;361:353-389.

26 Campanella M, Parker N, Tan CH, Hall AM, Duchen MR: IF(1): setting the pace of the F(1)F(o)-ATP synthase. Trends Biochem Sci 2009;34:343-350.

27 Marshall LE, Himes RH: Rotenone inhibition of tubulin self-assembly. Biochim Biophys Acta 1978;543:590-594. 
28 Ren Y, Feng J: Rotenone selectively kills serotonergic neurons through a microtubule-dependent mechanism. J Neurochem 2007;103: 303-311.

-29 Brinkley BR, Barham SS, Barranco SC, Fuller GM: Rotenone inhibition of spindle microtubule assembly in mammalian cells. Exp Cell Res 1974;85:41-46.

-30 Martin-Hernandez E, Garcia-Silva MT, Vara J, Campos Y, Cabello A, Muley R, Del Hoyo $\mathrm{P}$, Martin MA, Arenas J: Renal pathology in children with mitochondrial diseases. Pediatr Nephrol 2005;20:1299-1305.

-31 Izzedine H, Launay-Vacher V, Isnard-Bagnis C, Deray G: Drug-induced Fanconi's syndrome. Am J Kidney Dis 2003;41:292-309.

-32 Lino M, Binaut R, Noel LH, Patey N, Rustin P, Daniel L, Serpaggi J, Varaut A, Vanhille P, Knebelmann B, Grunfeld JP, Fakhouri F: Tubulointerstitial nephritis and Fanconi syndrome in primary biliary cirrhosis. Am J Kidney Dis 2005;46:e41-e46.

33 Foreman JW, Benson LL, Wellons M, Avner ED, Sweeney W, Nissim I, Nissim I: Metabolic studies of rat renal tubule cells loaded with cystine: the cystine dimethylester model of cystinosis. J Am Soc Nephrol 1995;6: 269-272.

>34 Roth KS, Carter BE, Higgins ES: Succinylacetone effects on renal tubular phosphate metabolism: a model for experimental renal Fanconi syndrome. Proc Soc Exp Biol Med 1991;196:428-431.

35 Gullans SR, Brazy PC, Soltoff SP, Dennis VW, Mandel LJ: Metabolic inhibitors: effects on metabolism and transport in the proximal tubule. AJP - Renal Physiol 1982; 243:F133-F140.

\36 Coor C, Salmon RF, Quigley R, Marver D, Baum M: Role of adenosine triphosphate (ATP) and NaK ATPase in the inhibition of proximal tubule transport with intracellular cystine loading. J Clin Invest 1991;87:955961.

>37 Gstraunthaler G, Seppi T, Pfaller W: Impact of culture conditions, culture media volumes, and glucose content on metabolic properties of renal epithelial cell cultures: are renal cells in tissue culture hypoxic? Cell Physiol Biochem 1999;9:150-172.
38 Kim JW, Dang CV: Cancer's molecular sweet tooth and the Warburg effect. Cancer Res 2006;66:8927-8930

39 Kempson SA, Kunkler KJ, Murer H: Iodoacetate action on endocytic uptake of different fluid-phase markers by OK renal epithelial cells. Biochim Biophys Acta 1991;1091:324328.

40 Webb JL: Enzyme and Metabolic Inhibitors. New York, Academic Press, 1966.

41 Podbilewicz B, Mellman I: ATP and cytosol requirements for transferrin recycling in intact and disrupted MDCK cells. EMBO J 1990;9:3477-3487.

42 Schmid SL, Carter LL: ATP is required for receptor-mediated endocytosis in intact cells. J Cell Biol 1990;111:2307-2318.

43 Dhani SU, Kim CP, Huan LJ, Bear CE: ATP depletion inhibits the endocytosis of ClC-2. J Cell Physiol 2008;214:273-280.

44 Liao JF, Perkins JP: Differential effects of antimycin A on endocytosis and exocytosis of transferrin also are observed for internalization and externalization of $\beta$-adrenergic receptors. Mol Pharmacol 1993;44:364-370.

-45 Wu X, Zhao X, Baylor L, Kaushal S, Eisenberg E, Greene LE: Clathrin exchange during clathrin-mediated endocytosis. J Cell Biol 2001;155:291-300.

46 Gekle M, Mildenberger S, Freudinger R, Schwerdt G, Silbernagl S: Albumin endocytosis in OK cells: dependence on actin and microtubules and regulation by protein kinases. Am J Physiol 1997;272:F668-F677.

47 Korn ED, Carlier MF, Pantaloni D: Actin polymerization and ATP hydrolysis. Science 1987;238:638-644.

48 Oda H, Stockert RJ, Collins C, Wang H, Novikoff PM, Satir P, Wolkoff AW: Interaction of the microtubule cytoskeleton with endocytic vesicles and cytoplasmic dynein in cultured rat hepatocytes. J Biol Chem 1995; 270:15242-15249.

-49 Gluck SL, Underhill DM, Iyori M, Holliday LS, Kostrominova TY, Lee BS: Physiology and biochemistry of the kidney vacuolar $\mathrm{H}+$ ATPase. Annu Rev Physiol 1996;58:427-445.

50 Scheel O, Zdebik AA, Lourdel S, Jentsch TJ: Voltage-dependent electrogenic chloride/ proton exchange by endosomal CLC proteins. Nature 2005;436:424-427.
51 Picollo A, Pusch M: Chloride/proton antiporter activity of mammalian CLC proteins ClC-4 and ClC-5. Nature 2005;436:420-423.

52 Clague MJ, Urbe S, Aniento F, Gruenberg J: Vacuolar ATPase activity is required for endosomal carrier vesicle formation. J Biol Chem 1994;269:21-24.

53 Griner RD, Schnellmann RG: Decreasing glycolysis increases sensitivity to mitochondrial inhibition in primary cultures of renal proximal tubule cells. In Vitro Cell Dev Biol Anim 1994;30A:30-34.

54 Molitoris BA, Sandoval RM: Intravital multiphoton microscopy of dynamic renal processes. Am J Physiol Renal Physiol 2005; 288:F1084-F1089.

-55 Hariharakrishnan J, Satpute RM, Prasad GB, Bhattacharya R: Oxidative stress mediated cytotoxicity of cyanide in LLC-MK2 cells and its attenuation by $\alpha$-ketoglutarate and N-acetyl cysteine. Toxicol Lett 2009;185: 132-141.

56 Ohnishi ST, Ohnishi T, Muranaka S, Fujita H, Kimura H, Uemura K, Yoshida K, Utsumi $\mathrm{K}$ : A possible site of superoxide generation in the complex I segment of rat heart mitochondria. J Bioenerg Biomembr 2005;37:1-15.

57 Okun JG, Lummen P, Brandt U: Three classes of inhibitors share a common binding domain in mitochondrial complex I (NADH:ubiquinone oxidoreductase). J Biol Chem 1999;274:2625-2630.

58 Ino T, Nishioka T, Miyoshi H: Characterization of inhibitor binding sites of mitochondrial complex I using fluorescent inhibitor. Biochim Biophys Acta 2003;1605:15-20.

59 Hirst J, King MS, Pryde KR: The production of reactive oxygen species by complex I. Biochem Soc Trans 2008;36:976-980.

60 Hamm-Alvarez SF, Sheetz MP: Microtubule-dependent vesicle transport: modulation of channel and transporter activity in liver and kidney. Physiol Rev 1998;78:11091129.

61 Elkjaer ML, Birn H, Agre P, Christensen EI, Nielsen S: Effects of microtubule disruption on endocytosis, membrane recycling and polarized distribution of aquaporin-1 and gp330 in proximal tubule cells. Eur J Cell Biol 1995;67:57-72. 